\title{
Novel KRAS mutation in an unusual tectal low- grade glioma
}

\author{
Sharon Wulfovich, ${ }^{1}$ Suzanne Tucker, ${ }^{2}$ Michael Levy, ${ }_{1}$ John Ross Crawford ${ }^{4}$
}

${ }^{1}$ School of Medicine University of California San Diego Health Sciences, San Diego, California, USA

${ }^{2}$ Rady Children's Hospital, San Diego, California, USA

${ }^{3}$ Neurosurgery, University of California San Diego, San Diego, California, USA

${ }^{4}$ Neurosciences and Pediatrics, University of California San Diego, La Jolla, California, USA

\section{Correspondence to} Dr John Ross Crawford; jrcrawford@ucsd.edu

Accepted 17 March 2021

Check for updates

(c) BMJ Publishing Group Limited 2021. No commercial re-use. See rights and permissions. Published by BMJ.

To cite: Wulfovich $S$, Tucker S, Levy M, et al. BM」 Case Rep 2021:14:e242306. doi:10.1136/bcr-2021 242306

\section{DESCRIPTION}

An 8-year-old boy with no significant medical history or family history presented with 1-2 weeks of decreased visual acuity and blurry vision. The patient denied any headaches, vomiting, dizziness, seizures or weakness. Physical examination was significant for poorly reactive pupils, constricted bilateral visual fields and bilateral papilledema. MRI (figure 1A,B) revealed a non-enhancing tectal mass with associated obstructive hydrocephalus and a second lesion in the left middle cerebellar peduncle. MRI of the spine was normal. The patient underwent a robotic-guided biopsy of the tectal mass and endoscopic third ventriculostomy. Neuropathology (figure 2A,B) demonstrated an infiltrative mildly hypercellular glial neoplasm composed of elongated glial cells with mild nuclear pleomorphism. Small collections of eosinophilic granular bodies were identified. Vascular proliferation, necrosis or increased mitotic activity were not identified on higher power. There were several neurons present throughout the biopsy indicative of infiltration. Immunohistochemistry for glial fibrillar acidic protein (GFAP) was diffusely positive. Antigen KI-67 (Ki-67) had a focal positivity of approximately $3 \%$. These findings were consistent with a tectal low-grade astrocytoma with histological features of pilocytic astrocytoma and evidence of infiltration (WHO Grade I-II). Next generational sequencing was significant for a Kirsten rat sarcoma viral oncogene homolog (KRAS) c181C > A mutation. Variants of unknown significance in $\mathrm{Cbl}$ Proto-Oncogene B $(C B L B)(\mathrm{c} 1877 \mathrm{~A}>\mathrm{G})$ adenomatous polyposis coli gene (APC) (c5026A $>\mathrm{G})$

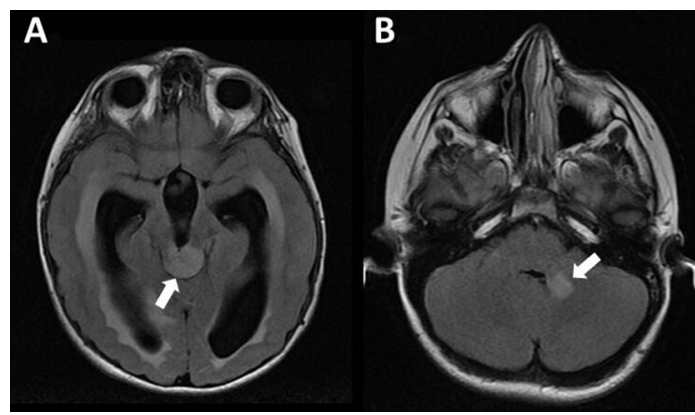

Figure 1 Neuroradiological features of tectal neoplasm with associated obstructive hydrocephalus. (A) Axial fluid-attenuated inversion recovery magnetic resonance sequencing reveals a non-enhancing tectal neoplasm (arrow) with associated acute obstructive hydrocephalus as evidenced by transependymal oedema. (B) An additional non-contiguous, non-enhancing lesion is noted in the left middle cerebellar peduncle (arrow).

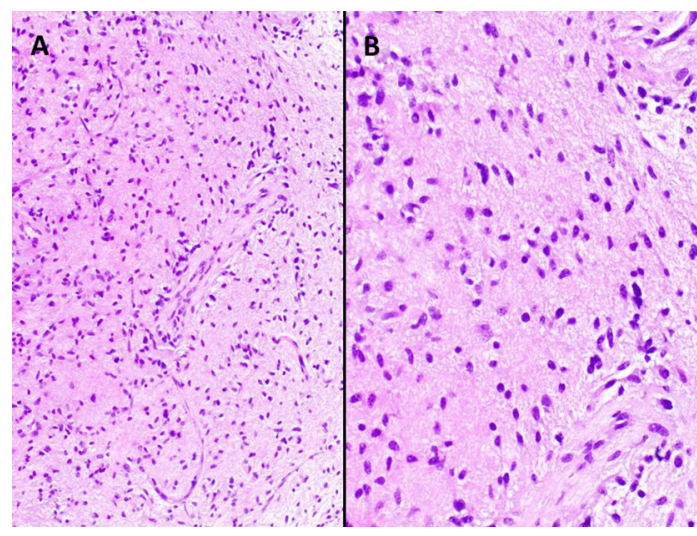

Figure 2 Neuropathological features of tectal glioma. (A) H\&E staining demonstrates an infiltrative mildly hypercellular glial neoplasm composed of elongated glial cells with mild nuclear pleomorphism (20x magnification). Small collections of eosinophilic granular bodies were identified (not pictured). (B) Vascular proliferation, necrosis or increased mitotic activity were not identified on higher power (40x magnification).

were also detected. Following surgery, the patient had mild improvement on his bilateral papilledema. However, the patient continues with stable visual deficits and no progression of disease following 3 years of routine neuroimaging in the absence of therapy.

Tectal gliomas are rare low-grade tumours that are more often seen in the paediatric population. The most frequent clinical presentation are symptoms related to an increased intracranial pressure. Most tectal gliomas have similar histopathological features similar to pilocytic astrocytoma and diffuse astrocytoma. ${ }^{1} \quad$ Immunohistochemically, tectal gliomas are characteristically diffusely and strongly positive for GFAP and OLig2, while having minimal Ki67 staining. However, tectal gliomas have a unique DNA methylation profile. ${ }^{1}$ Additionally, tectal gliomas have a high frequency of $\mathrm{v}$-raf murine sarcoma viral oncogene homolog B1 (BRAF) mutations (KIAA1549-BRAF, BRAF V600E and BRAF T599dup), although at lower rates (especially the KIAA1549-BRAF fusion) compared with pilocytic astrocytoma. ${ }^{2}$ Moreover, high frequency of spot KRAS G12R mutations has also been identified and tectal gliomas with both $B R A F$ and KRAS mutations have also been reported. ${ }^{2}$

Other rare KRAS mutations like E63K have also been identified.

KRAS is involved in many signalling cascades (ie, Phosphoinositide 3-Kinase (PI3K)/AKT axis, mitogen-activated protein kinase (MAPK) kinase 
cascade and Janus kinase-signal transducers and activators of transcription (JAK/STAT3)) and is therefore involved in many cellular processes. When mutated it acquires oncogenic properties that allow for perpetual activation of the RAS molecules, leading to unregulated cellular proliferation. ${ }^{4}$ Although KRAS mutations have been implicated in numerous cancers and is the most frequently involved MAPK oncogene across all cancer types, ${ }^{5}$ KRAS mutations are infrequent in paediatric central nervous system (CNS) tumours. ${ }^{6}$

While the ideal approach to KRAS mutant targeted therapy for glioma is not clear, consideration of downstream MAPK inhibition may be worthwhile.

The KRAS c181C>A mutation found in our patient has not been reported to the best of our knowledge and it is unclear

\section{Learning points}

- Tectal gliomas are rare low-grade tumours that are more often seen in the paediatric population and associated with obstructive hydrocephalus.

- Tectal gliomas may be associated with a diverse set of genetic and epigenetic characteristics.

- We report the first case of KRAS c181c $>$ A mutation in a tectal low-grade astrocytoma. what role this mutation or the other mutations identified in CBLB and APC play in tumour growth. Our findings add to the genetic diversity of paediatric tectal glioma.

Contributors SW, ST, ML and JRC were responsible for the design and writing of the manuscript.

Funding The authors have not declared a specific grant for this research from any funding agency in the public, commercial or not-for-profit sectors.

Competing interests None declared.

Patient consent for publication Obtained.

Provenance and peer review Not commissioned; externally peer reviewed.

\section{REFERENCES}

1 Liu APY, Harreld JH, Jacola LM, et al. Tectal glioma as a distinct diagnostic entity: a comprehensive clinical, imaging, histologic and molecular analysis. Acta Neuropathol Commun 2018;6:101.

2 Chiang J, Li X, Liu APY, et al. Tectal glioma harbors high rates of KRAS G12R and concomitant KRAS and BRAF alterations. Acta Neuropathol 2020;139:601-2.

3 Chau LQ, Levy ML, Crawford JR. Unusual KRAS missense mutation (p.E63K) in patient with juvenile pilocytic astrocytoma of the tectum. BMJ Case Rep 2019;12:e228128.

4 Jancík S, Drábek J, Radzioch D, et al. Clinical relevance of KRAS in human cancers. J Biomed Biotechnol 2010:2010:1-13.

5 Zehir A, Benayed R, Shah RH, et al. Mutational landscape of metastatic cancer revealed from prospective clinical sequencing of 10,000 patients. Nat Med 2017:23:703-13.

6 Ryall S, Zapotocky M, Fukuoka K, et al. Integrated molecular and clinical analysis of 1,000 pediatric low-grade gliomas. Cancer Cell 2020;37:569-83.

7 Jones DTW, Kieran MW, Bouffet E, et al. Pediatric low-grade gliomas: next biologically driven steps. Neuro Oncol 2018:20:160-73.

Copyright 2021 BMJ Publishing Group. All rights reserved. For permission to reuse any of this content visit

https://www.bmj.com/company/products-services/rights-and-licensing/permissions/

BMJ Case Report Fellows may re-use this article for personal use and teaching without any further permission.

Become a Fellow of BMJ Case Reports today and you can:

- Submit as many cases as you like

- Enjoy fast sympathetic peer review and rapid publication of accepted articles

- Access all the published articles

- Re-use any of the published material for personal use and teaching without further permission

Customer Service

If you have any further queries about your subscription, please contact our customer services team on +44 (0) 2071111105 or via email at support@bmj.com.

Visit casereports.bmj.com for more articles like this and to become a Fellow 